\title{
Toxicity and Some Biological Effects of Emamectin Benzoate, Novaluron and Diflubenzuron against Cotton Leafworm
}

\author{
Mervat H. A. Metayi ${ }^{1}$, Moataza A. M. Ibrahiem ${ }^{1}$ and Dalia A. El-Deeb ${ }^{2}$
}

\begin{abstract}
Toxicity and sublethal effects of emamectin benzoate, novaluron and diflubenzuron were evaluated against the $2^{\text {nd }}$ instar larvae of cotton leafworm (CLW). The joint toxic action of emamectin benzoate with novaluron or diflubenzuron was carried out. Emamectin benzoate $\left(\mathrm{LC}_{50}\right.$ $=0.014 \mathrm{mg} \mathrm{L}^{-1}$ ) was 264.3 and 5707.1 times more toxic than novaluron $\left(\mathrm{LC}_{50}=3.7 \mathrm{mg} \mathrm{L}^{-1}\right)$ and diflubenzuron $\left(\mathrm{LC}_{50}=79.9 \mathrm{mg} \mathrm{L^{-1 }}\right)$, respectively. Novaluron was approximately 21.6 times more toxic than diflubenzuron. After 24 hrs of exposure, all mixtures of emamectin benzoate (at $\mathrm{LC}_{10}$ or $\mathrm{LC}_{25}$ ) with novaluron or diflubenzuron (at $\mathrm{LC}_{10}$ or $\mathrm{LC}_{25}$ ) resulted in antagonistic effects with co-toxicity factors (CTFs) ranged between $\mathbf{- 2 5}$ to -700 except the mixture of emamectin benzoate at $L^{-25}$ with novaluron at $\mathrm{LC}_{10}(\mathrm{CTF}=60)$. Mixtures of emamectin benzoate at $\mathrm{LC}_{10}$ with novaluron at $\mathrm{LC}_{10}$ and emamectin benzoate at $\mathbf{L C}_{25}$ with novaluron at $\mathbf{L C}_{25}$ resulted in potentiating effects after 48,72 and $96 \mathrm{hrs}$ of exposure. On the other hand, all mixtures of emamectin benzoate with diflubenzuron resulted in antagonistic effects. Emamectin benzoate, novaluron and diflubenzuron at the two sublethal concentrations reduced average larval weight, average time to the pupation, \%pupation, pupal mean weight and \%adult emergence compared to control. Results of this study verified the lethal and sublethal effects of emamectin benzoate, novaluron and diflubenzuron on the larval stage of $S$. littoralis, which negatively affect some biological parameters and insect population can be negatively affected. Emamectin benzoate, novaluron and diflubenzuron can be used for $S$. littoralis control and in resistance management programs, because their mode of action is different from pyrethroid, carbamate and organophosphate insecticides.
\end{abstract}

Keywords: Biological Effects, Emamectin benzoate, Novaluron, Diflubenzuron, Cotton Leafworm

\section{INTRODUCTION}

Cotton leafworm, Spodoptera littoralis (Boisduval), is one of the most destructive agricultural lepidopterous pests of cotton and vegetable plants in Egypt (Hatem et al., 2009), causing considerable damage by feeding on leaves, fruiting points, flower buds and, occasionally, also on bolls. So, it requires several insecticide applications to control. In Egypt, management of CLW has depended on preserving and extending the insecticide efficacy based on rotating various insecticides including organophosphates, carbamates, insect growth regulators, and pyrethroids every year

\footnotetext{
${ }^{1}$ Plant Protection Research Institute, Arc, Sabahia, Alexandria, Egypt. ${ }^{2}$ Central Pesticides Laboratory, Sabahia Station, Alexandria Egypt.

Received November 3, 2015, Accepted December 8, 2015
}

(Temerak, 2002). Extensive use of insecticides has selected many insecticide resistant insect populations causing a severe problem in pest management programs of the world. So, there is a greater need to develop alternative or additional techniques, which would allow a rational use of pesticides and provides adequate crop protection for sustainable food, feed and fiber production. Among the most promising alternative to conventional insecticides, is the avermectin insecticide group and insect growth regulators.

Emamectin benzoate is novel semi-synthetic derivative of the natural product abamectin from the avermectin family of 16-membered macrocyclic lactones. This epi-methyl amino derivative is very effective against a broad spectrum of lepidopteran pests with good field efficacy and lack of cross-resistance with other commercially-used pesticides (White et al., 1997). IGRs were developed to mimic, block or otherwise interact with the hormonal system of insects (Oetken et al., 2004). These include the juvenile hormone analogues, the ecdysone agonists and the chitin synthesis inhibitors (CSIs) (Graf, 1993; Tunaz and Uygun, 2004). Among the chitin synthesis inhibitors, acylureas (BPUs) are gaining importance in insect pest control because they are relatively harmless to natural enemies (Furlong et al., 1994). The use of insecticides may result in multiple sublethal effects on insect pests, along with direct mortality, because of the different doses with which individual insects come into contact in the field (Singh and Marwaha, 2000). Therefore, the objectives of the present study were to investigate the toxicity of emamectin benzoate, novaluron and diflubenzuron against the $2^{\text {nd }}$ instar larvae of cotton leafworm. The compatibility of mixing emamectin benzoate with novaluron or diflubenzuron was carried out. Finally, the sublethal effects of emamectin benzoate, novaluron and diflubenzuron on some biological aspects of S. littoralis were also studied.

\section{MATERIALS AND METHODS}

Experimental insect: Larvae of S. littoralis were reared on castor bean leaves under lab conditions $\left(27 \pm 2{ }^{\circ} \mathrm{C}\right.$, RH $65 \%$ ) for several years avoiding exposure to any type of pesticides according to the method of Eldefrawi et al., (1964). The second instar larvae (average of 
weight was $2.3 \pm 0.1 \mathrm{mg}$ per larva) were used in the bioassay.

Tested insecticides: Emamectin benzoate $\left(\right.$ Basha $^{\circledR}$ $1.9 \%$ EC) was provided by Elhelb for Pesticides and Chemicals Co., novaluron $\left(\right.$ Roxy $^{\circledR} \quad 10 \%$ EC) was provided by Mytrade Co., and diflubenzuron (Diflurite ${ }^{\circledR}$ $25 \% \mathrm{WP}$ ) was provided by Misr for Agricultural Development Co.

Toxicity of the tested insecticides against the $2^{\text {nd }}$ instar larvae of $S$. littoralis and determination of sublethal concentrations: Toxicity of the forementioned formulated insecticides against the $2^{\text {nd }}$ instar larvae of $S$. littoralis was evaluated. Homogenous pieces of the castor bean leaves were dipped in a series of the insecticides concentrations for $10 \mathrm{sec}$, held vertically to allow excess solution to drip off and dried at room temperature. Treated castor bean leaf pieces were transferred to a plastic cups, and the appropriate number (10 larvae in each cup) of starved larvae were placed. Each concentration was replicated three times. Mortality percentages were recorded after $96 \mathrm{hrs}$ of treatment, corrected according to Abbott equation (Abbott, 1925) and subjected to probit analysis (Finney, 1971).

Joint toxic action of emamectin benzoate with novaluron or diflubenzuron against the $2^{\text {nd }}$ instar larvae of $\boldsymbol{S}$. littoralis: Joint toxic action of emamectin benzoate with novaluron or diflubenzuron against the $2^{\text {nd }}$ instar larvae of $S$. littoralis was investigated. Emamectin benzoate was mixed with novaluron or diflubenzuron at different concentrations. $\mathrm{LC}_{25}$ of emamectin benzoate was mixed with the $\mathrm{LC}_{25}$ or $\mathrm{LC}_{10}$ of novaluron or diflubenzuron. Also, $\mathrm{LC}_{10}$ of emamectin benzoate was mixed with $\mathrm{LC}_{25}$ or $\mathrm{LC}_{10}$ of novaluron or diflubenzuron. Three control groups were subjected to calculate the expected mortalities. Cotoxicity factors (Mansour et al., 1966) were calculated as follows:

Co-toxicity factor $(\mathrm{CTF})=$

$$
\frac{\text { observed \% mortality - exp ected \% mortality }}{\exp \text { ected } \% \text { mortality }}
$$

Table 1. Toxicity of emamectin benzoate, novaluron and diflubenzuron against $2^{\text {nd }}$ instar larvae of cotton leafworm after $96 \mathrm{hrs}$ of exposure

\begin{tabular}{lcccc}
\hline Treatment & $\begin{array}{c}\mathbf{L C}_{\mathbf{5 0}}\left(\mathbf{m g ~ L}^{-1}\right) \\
\text { confidence limits }\end{array}$ & $\begin{array}{c}\mathbf{L C}_{\mathbf{2 5}}\left(\mathbf{m g ~ L}^{-1}\right) \\
\text { confidence limits }\end{array}$ & $\begin{array}{c}\mathbf{L C}_{\mathbf{1 0}}\left(\mathbf{m g ~ L}^{-1}\right) \\
\text { confidence limits }\end{array}$ & Slope \pm SE \\
\hline Emamectin benzoate & 0.014 & 0.007 & 0.004 & $2.4 \pm 0.27$ \\
Novaluron & $(0.0087-0.021)$ & $(0.0025-0.0082)$ & $(0.0007-0.004)$ & $1.27 \pm 0.13$ \\
Diflubenzuron & 3.7 & 1.07 & 0.36 & \\
& $(3.0-4.7)$ & $(0.8-1.4)$ & $(0.201-0.53)$ & $1.09 \pm 0.09$ \\
\hline
\end{tabular}

This factor was used to categorize the results into three categories as follow: Co-toxicity factors $\geq+20$ meant potentiation; co-toxicity factors $<-20$ meant antagonism; and co-toxicity factors between -20 and +20 meant additive effect.

Effects of sublethal concentrations of emamectin benzoate, novaluron and diflubenzuron on some biological parameters of $\boldsymbol{S}$. littoralis:

Castor bean leaves were soaked in determined $\mathrm{LC}_{25}$ and $\mathrm{LC}_{10}$ equivalent concentrations for tested insecticides. Four hundred $2^{\text {nd }}$ instar larvae $(2.3 \pm 0.1$ $\mathrm{mg} /$ larva) in 4 replicates was used for each treatment and provided with treated leaves. After $24 \mathrm{hrs}$, surviving larvae were transferred to jars containing fresh untreated leaves and observed daily for pupation and adult emergence. Pupae were sexed and weighed $24 \mathrm{hrs}$ after formation. Larval and pupal durations were determined. Also, larval and pupal weights, percentages of pupation and adult emergence were recorded.

Statistical analysis: Estimates of $\mathrm{LC}_{50}$ and their $95 \%$ fiducial limits were obtained using the POLO program (Russell et al., 1977) based on Finney (1971). The criterion used to estimate the differences between $\mathrm{LC}_{50}$ values was non-overlap of their $95 \%$ confidence intervals. All other quantitative estimations were replicated four times and the values are expressed as mean \pm standard error. The SAS 8.0 software was used for analysis of the data obtained from each experiment and the means were tested for significant differences by Duncan's multiple range tests at $P=0.05$.

\section{RESULTS}

Toxicity of emamectin benzoate, novaluron and diflubenzuron against $2^{\text {nd }}$ instar larvae of $S$. littoralis:

Susceptibility of $2^{\text {nd }}$ instar larvae of $S$. littoralis to emamectin benzoate, novaluron and diflubenzuron after $96 \mathrm{hrs}$ of exposure is presented in Table (1). Emamectin benzoate $\left(\mathrm{LC}_{50}=0.014 \mathrm{mg} \mathrm{\textrm {L } ^ { - 1 }}\right)$ was approximately 264.3 and 5707.1 times more toxic than novaluron $\left(\mathrm{LC}_{50}\right.$ $\left.=3.7 \mathrm{mg} \mathrm{L}^{-1}\right)$ and diflubenzuron $\left(\mathrm{LC}_{50}=79.9 \mathrm{mg} \mathrm{L}^{-1}\right)$, respectively. Novaluron was approximately 21.6 times more toxic than diflubenzuron (Table 1). 
The $\mathrm{LC}_{10}$ and $\mathrm{LC}_{25}$ values after $96 \mathrm{hrs}$ of exposure were 0.004 and $0.007 \mathrm{mg} \mathrm{L}^{-1}$ for emamectin benzoate, 0.36 and $1.07 \mathrm{mg} \mathrm{L}^{-1}$ for novaluron, and for diflubenzuron were 5.4 and $19.4 \mathrm{mg} \mathrm{L}^{-1}$, respectively (Table 1).

Joint toxic action of emamectin benzoate with novaluron or diflubenzuron against the $2^{\text {nd }}$ instar larvae of $S$. littoralis:

To determine the effect of applying mixtures of emamectin benzoate at concentrations equivalent to $\mathrm{LC}_{10}$ or $\mathrm{LC}_{25}$ with novaluron or diflubenzuron at $\mathrm{LC}_{10}$ or $\mathrm{LC}_{25}, 50 \%$ or $35 \%$ or $20 \%$ mortality was expected to result when the mixture was used. Since the average weights of the $2^{\text {nd }}$ instar larvae used in each test varied, thus, the expected mortality for the concentrations applied in every test varied accordingly. So, the expected mortality was calculated for each insecticide in the mixture in every test by treating the larvae by each one alone. Therefore, the expected mortality for the mixture of two insecticides was the sum of the mortalities of each of the concentrations used in the mixture. The joint toxic action of emamectin benzoate with novaluron or diflubenzuron at different concentrations at different exposure times is shown in Tables (2, 3, 4 and 5). After $24 \mathrm{hrs}$ of exposure, all mixtures of emamectin benzoate (at $\mathrm{LC}_{10}$ or $\mathrm{LC}_{25}$ ) with novaluron or diflubenzuron (at $\mathrm{LC}_{10}$ or $\mathrm{LC}_{25}$ ) resulted in antagonistic effect with co-toxicity factors (CTFs) ranged between -25 to -100 except the mixture of emamectin benzoate at $\mathrm{LC}_{10}$ with novaluron at $\mathrm{LC}_{10}$ $(\mathrm{CTF}=60)($ Table 2$)$. Mixture of emamectin benzoate at $\mathrm{LC}_{10}$ with novaluron at $\mathrm{LC}_{10}$ resulted in potentiating effects with CTFs 100, 33.3 and 95.6 after 48, 72 and $96 \mathrm{hrs}$ of exposure (Tables 3, 4 and 5). Also, mixture of emamectin benzoate at $\mathrm{LC}_{25}$ with novaluron at $\mathrm{LC}_{25}$ resulted in potentiating effect with CTFs of 41.3, 46.9 and 32.4 after 48, 72 and $96 \mathrm{hrs}$ of exposure (Tables 3, 4 and 5). On the other hand, all mixtures of emamectin benzoate with diflubenzuron resulted in antagonistic effects after all exposure times (Tables 2, 3, 4 and 5).

Sublethal effects of emamectin benzoate, novaluron and diflubenzuron on some biological aspects of $S$. littoralis:

Sublethal effects of tested insecticides against $S$. littoralis larvae are presented in Tables (6 and 7). The average weight of treated larvae was decreased significantly compared to control during the observation period. It is clear that, the higher concentration of all tested insecticides $\left(\mathrm{LC}_{25}\right)$ were significantly the highest in the effect on the larval weight. When larvae were treated with emamectin benzoate at $\mathrm{LC}_{25}\left(0.0074 \mathrm{mgL}^{-}\right.$ $\left.{ }^{1}\right)$, the larval weight averages were $35.6,129.7$ and $430.3 \mathrm{mg} /$ larva compared to $47.7,189.2$ and $610.6 \mathrm{mg}$
/ larva in control after 5, 10 and 15 days of treatment, respectively. The larval weight averages were 37.1, 140.2 and $434.5 \mathrm{mg} /$ larva, and 40.4, 145.5 and 439.0 $\mathrm{mg} /$ larva when larvae were treated with $\mathrm{LC}_{25}$ of novaluron $\left(1.07 \mathrm{mgL}^{-1}\right)$ and diflubenzuron $\left(19.4 \mathrm{mgL}^{-1}\right)$ after 5, 10 and 15 days of treatment, respectively (Table $6)$.

The average time of larval duration at concentrations equivalent to the $\mathrm{LC}_{10}$ and $\mathrm{LC}_{25}$ of novaluron and diflubenzuron treatments were significantly longer than those of control treatment. These times were 23.2 and 23.9 days for novaluron and 22.8 and 23.7 days for diflubenzuron at $\mathrm{LC}_{10}$ and $\mathrm{LC}_{25}$, respectively, where it was 17.4 days for control. Larval duration for larvae given concentrations equivalent to the $\mathrm{LC}_{10}$ and $\mathrm{LC}_{25}$ of emamectin benzoate treatments did not differ significantly compared to larvae given control treatment (Table 6).

Sulethal concentrations of tested insecticides had a considerable effect on \%pupation (Table 6). The $\mathrm{LC}_{25}$ treatment of novaluron gave the lowest pupation percentage $62.7 \%$ compared to $98.4 \%$ in control treatment. Also, significant decrease in pupation percentage was achieved with the $\mathrm{LC}_{10}$ of novaluron $(73.6 \%)$, the $\mathrm{LC}_{10}$ and $\mathrm{LC}_{25}$ of emamectin benzoate (82.6 and $78.6 \%$, respectively) and the $\mathrm{LC}_{10}$ and $\mathrm{LC}_{25}$ of diflubenzuron (77.1 and 70.3\%, respectively) compared to control treatment (98.4\%).

As shown in Table (7), all treatments significantly suppressed the pupal mean weight compared to control treatment. The weight averages of pupae were 280.2 and $261.1 \mathrm{mg} /$ pupa at the $\mathrm{LC}_{10}$ and $\mathrm{LC}_{25}$ of emamectin benzoate treatments, respectively, compared to $298.5 \mathrm{mg}$ / pupa at control treatment. In case of $\mathrm{LC}_{10}$ and $\mathrm{LC}_{25}$ of novaluron treatments, pupae weight averages were 275.6 and $253.4 \mathrm{mg} /$ pupa, respectively. Finally, pupae weight averages were 273.6 and $256.5 \mathrm{mg} /$ pupa in the $\mathrm{LC}_{10}$ and $\mathrm{LC}_{25}$ of diflubenzuron treatments, respectively. However, pupal duration did not change significantly in all treatments compared to control (Table 7). Reduction in the adult emergence was significantly achieved by all treatments. Adult emergence was 89.4 and $77.5 \%$ in the $\mathrm{LC}_{10}$ and $\mathrm{LC}_{25}$ of emamectin benzoate treatments, respectively, compared to $96.0 \%$ in the control treatments. The $\mathrm{LC}_{25}$ of both novaluron and diflubenzuron achieved the highest reduction in the adult emergence, where the adult emergence was 66.4 and $68.3 \%$, respectively (Table 7 ). On the other hand, pupal duration did not differ significantly in all insecticides treatments compared to control treatment (Table 7). 
Table 2. Joint toxic action of emamectin benzoate with novaluron or diflubenzuron against $2^{\text {nd }}$ instar larvae of cotton leafworm after $48 \mathrm{hrs}$ of exposure

\begin{tabular}{lccc}
\hline Treatments & Expected \% Mortality & Observed\% Mortality & CTF \\
\hline E*.Benzoate $\mathrm{LC}_{10}+$ Novaluron $\mathrm{LC}_{10}$ & 2 & 5 & 60 \\
E.Benzoate $\mathrm{LC}_{10}+$ Novaluron $\mathrm{LC}_{25}$ & 10 & 4 & -60 \\
E.Benzoate $\mathrm{LC}_{25}+$ Novaluron $\mathrm{LC}_{10}$ & 12 & 0 & -100 \\
E.Benzoate $\mathrm{LC}_{25}+$ Novaluron $\mathrm{LC}_{25}$ & 22 & 16 & -27.3 \\
E.Benzoate $\mathrm{LC}_{10}+$ Diflubenzuron $\mathrm{LC}_{10}$ & 1 & 0 & -100 \\
E.Benzoate $\mathrm{LC}_{10}+$ Diflubenzuron $\mathrm{LC}_{25}$ & 5 & 4 & -25 \\
E.Benzoate $\mathrm{LC}_{25}+$ Diflubenzuron $\mathrm{LC}_{10}$ & 12 & 0 & -100 \\
E.Benzoate $\mathrm{LC}_{25}+$ Diflubenzuron $\mathrm{LC}_{25}$ & 17 & 8 & -64.7 \\
\hline
\end{tabular}
*E $=$ emamectin

Table 3. Joint toxic action of emamectin benzoate with novaluron or diflubenzuron against $2^{\text {nd }}$ instar larvae of cotton leafworm after 72 hrs of exposure

\begin{tabular}{lccc}
\hline Treatment & Expected \% Mortality & Observed\% Mortality & CTF \\
\hline E*.Benzoate $\mathrm{LC}_{10}+$ Novaluron $\mathrm{LC}_{10}$ & 10 & 20 & 100 \\
E.Benzoate $\mathrm{LC}_{10}+$ Novaluron $\mathrm{LC}_{25}$ & 18.3 & 12 & -34.4 \\
E.Benzoate $\mathrm{LC}_{25}+$ Novaluron $\mathrm{LC}_{10}$ & 20 & 8 & -60 \\
E.Benzoate $\mathrm{LC}_{25}+$ Novaluron $\mathrm{LC}_{25}$ & 28.3 & 40 & 41.3 \\
E.Benzoate $\mathrm{LC}_{10}+$ Diflubenzuron $\mathrm{LC}_{10}$ & 13 & 0 & -100 \\
E.Benzoate $\mathrm{LC}_{10}+$ Diflubenzuron $\mathrm{LC}_{25}$ & 25 & 20 & -20 \\
E.Benzoate $\mathrm{LC}_{25}+$ Diflubenzuron $\mathrm{LC}_{10}$ & 23 & 8 & -65.2 \\
E.Benzoate $\mathrm{LC}_{25}+$ Diflubenzuron $\mathrm{LC}_{25}$ & 35 & 8 & -77.1 \\
\hline
\end{tabular}

*E $=$ emamectin

Table 4. Joint toxic action of emamectin benzoate with novaluron or diflubenzuron against $2^{\text {nd }}$ instar larvae of cotton leafworm after $96 \mathrm{hrs}$ of exposure

\begin{tabular}{lccc}
\hline Treatment & Expected \% Mortality & Observed\% Mortality & CTF \\
\hline E*.Benzoate $\mathrm{LC}_{10}+$ Novaluron $\mathrm{LC}_{10}$ & 20 & 30 & 33.3 \\
E.Benzoate $\mathrm{LC}_{10}+$ Novaluron $\mathrm{LC}_{25}$ & 33 & 16 & -51.5 \\
E.Benzoate $\mathrm{LC}_{25}+$ Novaluron $\mathrm{LC}_{10}$ & 39 & 8 & -81.6 \\
E.Benzoate $\mathrm{LC}_{25}+$ Novaluron $\mathrm{LC}_{25}$ & 49 & 72 & 46.9 \\
E.Benzoate $\mathrm{LC}_{10}+$ Diflubenzuron $\mathrm{LC}_{10}$ & 20 & 8 & -60 \\
E.Benzoate $\mathrm{LC}_{10}+$ Diflubenzuron $\mathrm{LC}_{25}$ & 28 & 20 & -28.6 \\
E.Benzoate $\mathrm{LC}_{25}+$ Diflubenzuron $\mathrm{LC}_{10}$ & 36 & 12 & -67.7 \\
E.Benzoate $\mathrm{LC}_{25}+$ Diflubenzuron $\mathrm{LC}_{25}$ & 44 & 8 & -81.8 \\
\hline *E $=$ emarecti
\end{tabular}

Table 5. Joint toxic action of emamectin benzoate with novaluron or diflubenzuron against $2^{\text {nd }}$ instar larvae of cotton leafworm after $120 \mathrm{hrs}$ of exposure

\begin{tabular}{lccc}
\hline \multicolumn{1}{c}{ Treatment } & Expected \% Mortality & Observed\% Mortality & CTF \\
\hline E*.Benzoate $\mathrm{LC}_{10}+$ Novaluron $\mathrm{LC}_{10}$ & 23 & 45 & 95.6 \\
E.Benzoate $\mathrm{LC}_{10}+$ Novaluron $\mathrm{LC}_{25}$ & 48 & 32 & -33.3 \\
E.Benzoate $\mathrm{LC}_{25}+$ Novaluron $\mathrm{LC}_{10}$ & 43 & 12 & -91.2 \\
E.Benzoate $\mathrm{LC}_{25}+$ Novaluron $\mathrm{LC}_{25}$ & 68 & 90 & 32.4 \\
E.Benzoate $\mathrm{LC}_{10}+$ Diflubenzuron $\mathrm{LC}_{10}$ & 20 & 8 & -60 \\
E.Benzoate $\mathrm{LC}_{10}+$ Diflubenzuron $\mathrm{LC}_{25}$ & 33 & 28 & -45.5 \\
E.Benzoate $\mathrm{LC}_{25}+$ Diflubenzuron $\mathrm{LC}_{10}$ & 40 & 24 & -40 \\
E.Benzoate $\mathrm{LC}_{25}+$ Diflubenzuron $\mathrm{LC}_{25}$ & 53 & 8 & -84.9 \\
\hline
\end{tabular}


Table 6. Effect of emamectin benzoate, novaluron and diflubenzuron when applied to the $2^{\text {nd }}$ instar larvae of $\boldsymbol{S}$. littoralis on the larval weight gain, larval duration and \%pupation

\begin{tabular}{|c|c|c|c|c|c|c|}
\hline \multirow[t]{2}{*}{ Insecticide } & \multirow[t]{2}{*}{$\begin{array}{c}\text { Conc. } \\
\left(\mathrm{mg} \mathrm{L}^{-1}\right)\end{array}$} & \multicolumn{3}{|c|}{$\begin{array}{c}\text { Mean weight (mg/larva) } \pm \text { SE after different } \\
\text { days of treatment }\end{array}$} & \multirow{2}{*}{$\begin{array}{c}\text { Larval } \\
\text { duration } \\
\text { (days) } \pm \mathrm{SE}\end{array}$} & \multirow[t]{2}{*}{$\begin{array}{l}\text { Pupation (\%) } \\
\quad \pm \text { SE }\end{array}$} \\
\hline & & 5 & 10 & 15 & & \\
\hline Control & - & $47.7 a \pm 1.5$ & $189.2 \mathrm{a} \pm 3.2$ & $610.6 \mathrm{a} \pm 5.9$ & $17.4 b \pm 1.3$ & $98.4 \mathrm{a} \pm 1.0$ \\
\hline \multirow[t]{2}{*}{$E^{*}$. benzoate } & 0.004 & $41.2 b \pm 2.4$ & $163.9 c \pm 5.2$ & $518.2 \mathrm{c} \pm 4.5$ & $16.8 b \pm 0.6$ & $82.6 b \pm 1.6$ \\
\hline & 0.007 & $35.6 c \pm 2.1$ & $129.7 \mathrm{e} \pm 1.9$ & $430.3 d \pm 6.7$ & $18.3 b \pm 1.5$ & $78.6 c \pm 2.6$ \\
\hline \multirow[t]{2}{*}{ Novaluron } & 0.36 & $41.2 b \pm 1.4$ & $169.3 \mathrm{c} \pm 3.0$ & $509.3 c \pm 3.8$ & $23.2 \mathrm{a} \pm 1.8$ & $73.6 \mathrm{de} \pm 1.2$ \\
\hline & 1.07 & $37.1 \mathrm{c} \pm 0.7$ & $140.2 \mathrm{~d} \pm 4.3$ & $434.5 d \pm 3.6$ & $23.9 \mathrm{a} \pm 1.7$ & $62.7 f \pm 0.40$ \\
\hline \multirow[t]{2}{*}{ Diflubenzuron } & 5.04 & $43.0 \mathrm{~b} \pm 1.2$ & $177.6 b \pm 2.9$ & $540.6 b \pm 6.2$ & $22.8 \mathrm{a} \pm 1.4$ & $77.1 \mathrm{~cd} \pm 1.6$ \\
\hline & 19.4 & $40.4 b \pm 1.4$ & $145.5 d \pm 5.3$ & $439.0 \mathrm{~d} \pm 4.8$ & $23.7 \mathrm{a} \pm 0.8$ & $70.3 e \pm 1.7$ \\
\hline
\end{tabular}

Within a column, means possessing the same letter do not differ significantly at $P=0.05 . * \mathrm{E}=$ emamectin

Table 7. Effect of emamectin benzoate, novaluron and diflubenzuron when applied to the $2^{\text {nd }}$ instar larvae of $S$. littoralis on the pupal weight gain, pupal duration and \% adult emergence

\begin{tabular}{lcccc}
\hline Insecticide & $\begin{array}{c}\text { Conc. } \\
\left(\mathbf{m g ~ L}^{-\mathbf{1}}\right)\end{array}$ & $\begin{array}{c}\text { Pupal mean weight } \\
(\mathbf{m g} / \mathbf{p u p a}) \pm \mathbf{S E}\end{array}$ & $\begin{array}{c}\text { Pupal duration } \\
\text { (days) } \pm \mathbf{S E}\end{array}$ & $\begin{array}{c}\text { \%Adult emergence } \\
\pm \text { SE }\end{array}$ \\
\hline Control & - & $298.5 \mathrm{a} \pm 3.4$ & $9.7 \mathrm{a} \pm 0.6$ & $96.0 \mathrm{a} \pm 0.2$ \\
$\mathrm{E}^{*}$. benzoate & 0.004 & $280.2 \mathrm{~b} \pm 2.7$ & $9.5 \mathrm{a} \pm 0.4$ & $89.4 \mathrm{~b} \pm 2.3$ \\
& 0.007 & $261.1 \mathrm{c} \pm 3.1$ & $9.3 \mathrm{a} \pm 0.4$ & $77.5 \mathrm{~d} \pm 1.5$ \\
Novaluron & 0.36 & $275.6 \mathrm{~b} \pm 2.7$ & $9.4 \mathrm{a} \pm 0.5$ & $83.7 \mathrm{c} \pm 2.4$ \\
& 1.07 & $253.4 \mathrm{c} \pm 3.2$ & $9.7 \mathrm{a} \pm 0.5$ & $66.4 \mathrm{e} \pm 1.8$ \\
Diflubenzuro & 5.04 & $273.6 \mathrm{~b} \pm 2.4$ & $9.4 \mathrm{a} \pm 0.4$ & $80.5 \mathrm{~cd} \pm 2.1$ \\
$\mathrm{n}$ & & & & $68.3 \mathrm{e} \pm 1.7$ \\
\hline
\end{tabular}

Within a column, means possessing the same letter do not differ significantly at $P=0.05 .{ }^{*} \mathrm{E}=$ emamectin

\section{DISCUSSION}

Insect management strategies must be directed towards the use of insecticides that are none or less toxic to all environmental components including the beneficial arthropods. Emamectin benzoate is less toxic to most beneficial arthropods, especially when exposure occurs beyond one day after application (Lasota and Dybas, 1991). Also, IGRs which act as chitin synthesis inhibitors or juvenile hormone analogs have been regarded as excellent integrated control insecticides because of their specificity to target pests and their general safety to vertebrates (Deakle and Bradly, 1982). In the present study, toxicity of the semi-synthetic insecticide emamectin benzoate, and two IGR compounds novaluron and diflubenzuron against the $2^{\text {nd }}$ instar larvae of $S$. littoralis under the laboratory conditions were studied. Emamectin benzoate was approximately 264.3 and 5707.1 times more toxic than novaluron and diflubenzuron, respectively. Novaluron was approximately 21.6 times more toxic than diflubenzuron against the $2^{\text {nd }}$ instar larvae of S. littoralis after $96 \mathrm{hrs}$ of exposure. Argentine et al. (2002) reported high toxicity of emamectin benzoate against six species of Lepidoptera $\left(\mathrm{LC}_{90}\right.$ ranged from 0.0050 to $0.0218 \mu \mathrm{g} / \mathrm{ml}$ ). Previous studies also showed that emamectin benzoate was more toxic than some IGR compounds such as lufenuron and flufenoxuron against the $2^{\text {nd }}, 3^{\text {rd }}$ and $4^{\text {th }}$ instar larvae of $S$. littoralis (Saad et al., 2011).

The potentiating or synergistic effects that are likely to result from insecticides mixtures may allow a reduction in the insecticides field rates, delaying insecticide resistance and preserving natural enemies. In this study, mixtures of emamectin benzoate at $\mathrm{LC}_{10}$ with novaluron at $\mathrm{LC}_{10}$ and emamectin benzoate at $\mathrm{LC}_{25}$ with novaluron at $\mathrm{LC}_{25}$ resulted in potentiating effects. On the other hand, all mixtures of emamectin benzoate with diflubenzuron resulted in antagonistic effects. Saad et al., (2011) recorded an antagonistic effect when emamectin benzoate was mixed with the IGR insecticides lufenuron or flufenoxuron. Based on our results, mixtures of emamectin benzoate with novaluron (at equal concentrations) can be used for cotton leafworm larvae management. On the other hand, mixtures of emamectin benzoate with diflubenzuron should not be used for control the cotton leafworm larvae. At present, there is a great need for independent work to identify reduced dosage levels that provide adequate control. 
In field application of insecticides, some insects may be exposed to sublethal concentrations of the applied insecticide and many sublethal effects on insect pests can result from that exposure. Sublethal effects of emamectin benzoate, novaluron and diflubenzuron on some biological aspects of $S$. littoralis were carried out. Emamectin benzoate, novaluron and diflubenzuron at the two tested concentrations ( $\mathrm{LC}_{10}$ and $\left.\mathrm{LC}_{25}\right)$ significantly decreased the average weight of treated larvae, reduced pupation percentage, suppressed the pupal mean weight and reduced adult emergence rate compared to control during the observation period. Abro et al. (1993) found that abamectin (emamectin benzoate is a semi-synthetic from abamectin) significantly reduced weight gain (food consumption) by $4^{\text {th }}$ instars of P. xylostella at $\mathrm{LC}_{5}$. In another study, when Lymantria dispar L. larvae treated with either 5.0 or $1.0 \mathrm{ppm}$ abamectin had led to significantly reduced weight gain, indicating feeding cessation, also, delayed molting by at least $1 \mathrm{~d}$. Avermectin at all sublethal concentrations appeared to act as depressants (Deecher et al., 1990). In some dipteran larvae, sublethal doses of ivermectin have been reported to reduce pupation and emergence of adults (Strong, 1989).

Benzoylphenylureas (BPUs), are considered safe insecticides for humans and other mammals, since chitin is absent in these species (Apperson et al., 1978). Novaluron and diflubenzuron are types of IGRs that belong to benzoylurea. These insecticides disrupt chitin biosynthesis of the larval stages in susceptible insects (Ishaaya et al., 2003). Applications of novaluron or diflubenzuron may result in mortality by disrupting the molting process through inhibiting the formation of chitin. Additionally, reduced egg hatch has been documented from eggs treated with benzyl ureas as well as sublethal effects on the treated insects (Alyokhin and Choban, 2010, Elliot and Anderson, 1982), which was confirmed in this study. Novaluron and diflubenzuron negatively affect most of the growth and development parameters that tested when the $2^{\text {nd }}$ instar larvae of $S$. littoralis were treated by two sublethal concentrations. Abdel Rahman et al. (2007) reported that, when the $3^{\text {rd }}$ instar larvae of $S$. littoralis were treated with lufenuron (Benzoylphenylurea) the affected larvae ceased feeding within 48 hrs. Also, Adel (2012) recorded an antifeedant effect for lufenuron against $S$. littoralis larvae. This may be the main reason for larval and pupal weight reduction.

Finally, our results verified the lethal and sublethal effects of emamectin benzoate, novaluron and diflubenzuron on the larval stage of $S$. littoralis. The sublethal concentrations of these insecticides negatively affect some biological parameters of S. littoralis. These effects are very important from a practical point of view, because the insect population can be negatively affected. Fortunately, the mode of action of emamectin benzoate, novaluron and diflubenzuron is different from pyrethroid, carbamate and organophosphate insecticides. So, emamectin benzoate, novaluron and diflubenzuron can be used for S. littoralis control and resistance management programs.

\section{REFERENCES}

Abbott, W. S. 1925. A method for computing the effectiveness of an insecticide. J. Econ. Entomol. 18: 265-267.

Abdel Rahman, S.M., E.M. Hegazy, and A.E. Elwey. 2007. Direct and latent effects of two chitin synthesis inhibitors to Spodoptera littoralis larvae (Boisd.). AmericanEurasian J. Agric. Envron. Sci. 2: 457-464.

Abro, G.H.,T.S. Corbitt , P.T. Christie, and D.J. Wright. 1993. Sub-lethal effects of abamectin on Plutella xylostella L. and Spodoptera littoralis Boisduval larvae. Crop Prot. 12: 39-44.

Adel, M. M. 2012. Lufenuron Impair the Chitin Synthesis and Development of Spodoptera littoralis Bosid (Lepidoptera: Noctuidae). J. Appl. Sci. Res. 8: 2766-2775.

Alyokhin, A. and R. Choban. 2010. Maturity-dependent mortality of Colorado potato beetle eggs treated with novaluron. Am. J. Pot. Res. 87:557-560.

Apperson, C.S., C.H. Schaefer, A.E. Colwell, G.H. Werner, N.L. Anderson, E.F. Dupras and D.R. Longanecker. 1978. Effects of diflubenzuron on Chaoborus astictopus and nontarget organisms and persistence of diflubenzuron in lentic habitats. J. Econ. Entomol. 71: 521-527.

Argentine, J.A., R.K. Jansson, W.R. Halliday, D. Rugg and C.S. Jany. 2002. Potency, spectrum and residual activity of four new insecticides under glass house conditions. Florida Entomologist. 85: 552-562.

Deakle, J.P. and J.R. Bradly. 1982. Effects of early season applications of diflubenzuron and azinophosmethyl on population levels of certain arthropods in cotton fields. J. Ga. Entomol. Soc. 17: 200-204.

Deecher, D.C., J. Brezner and S.W. Tanenbaum. 1990. Sublethal effects of avermectin and milbemycin on the gypsy moth (Lepidoptera: Lymantriidae). J. Econ. Entomol. 83: 710-714.

Eldefrawi, M. E., A. Toppozada, N. Mansour and M. Zeid. 1964. Toxicological studies on the Egyptian cotton leafworm, Prodenia litura. I. Susceptibility of different larval instars of Prodenia to insecticides. J. Econ. Entomol. 57: 591-593.

Elliot, R., and D. W. Anderson. 1982. Factors influencing the activity of diflubenzuron against the codling moth, Laspeyresia pomonella (Lepidoptera: Olethreutida). Can. Entomol. 114:259-268.

Finney, D. J. 1971. Probit analysis, Cambridge Univ. Press, Cambridge. 
Furlong, M. J., H. J. Verkerk and D. J. Wright. 1994. Differential effects of the acylurea insect growth regulator, teflubenzuron on the adult of two endolarval parasitoids of Plutella xylostella, Costesia plutellae and Diadegma semiclousum. Pestic. Sci. 41: 359-364.

Graf, J. F. 1993. The role of insect growth regulators in arthropod control. Parasitol. 9: 471-474.

Hatem, A. E., H. B. Homam, R. A. M. Amer, S. S. M. AbdelSamad, H. A. Saleh and A. I. Hussien. 2009. Synergistic activity of several acids in binary mixtures with synthetic insecticides on Spodoptera littoralis (Boisduval). Boletin de Sanidad Vegetal Plagas. 35: 533-542.

Ishaaya, I., S. Kontsedalov and A. R. Horowitz. 2003. Novaluron (Rimon), a novel IGR: Potency and crossresistance. Arch. Insect Biochem. Physiol. 54:157-164.

Lasota, J.A. and R.A. Dybas. 1991. Avermectins, a novel class of compounds: implications for use in arthropod pest control. Annual Review of Entomology. 36: 91-117.

Mansour, N. A., M. E. Eldeferawi, A. Toppozada and M. Zeid. 1966. Toxicological studies on the Egyption cotton leafworm, Prodenia litura. VI. Potentiation and antagonism of organophosphorus and carbamate insecticides. J. Econ. Entomol., 59: 307-311.

Oetken, M., J. Bachmann, U. Schulte-Oehlmann and J. Oehlmann. 2004. Evidence for endocrine disruption in invertebrates. Int. Rev. Cytol. 236: 1-44.
Russell, R. M., J. L. Robertson and N. E. Savin. 1977. POLO: a new computer program for Probit analysis. Bulletin of the Entomological Society of America. 23: 209-213.

Saad, A.S.A., M.A. Massoud, M.K.A. Abu-Sholoua, H.K. Abou-Taleb and E. Kotb. 2011. Toxicity of emamectin benzoate and two IGR compounds against egg masses and different larval instars of cotton leafworm. J. Adv. Agric. Rees. 16: 271-282.

Singh, J. P. and K. K. Marwaha. 2000. Effects of sublethal concentrations of some insecticides on growth and development of maize stalk borer, Chilo partellus (Swinhoe) larvae. Shashpa. 7: 181-186.

Strong, L. 1989. Sequential latent effects of a sub-lethal dose of ivermectin on Calliphora vomitoria L. Pestic. Sci. 27: 253-260.

Temerak S. A. 2002. Historical records of field cotton leafworm (Spodoptera littoralis) resistance to conventional insecticides as influenced by the resistance programs in Egypt. Resistant Pest Management Newsletter. 12: 7-10.

Tunaz, H. and N. Uygun. 2004. Insect growth regulators for insect pest control. Turk. J. Agric. For. 28: 377-387.

White, S. M., D. M. Dunbar, R. Brown, B. Cartwright, D. Cox, C. Eckel, R. K. Jansson, P. K. Mookerjee, J. A. Norton, R. F. Peterson and V. R. Starner. 1997. Emamectin benzoate: a novel derivate for control of lepidopterous pests in cotton. In: Proceedings of Beltwide Cotton Conferences, New Orleans, pp.1078-1082. 


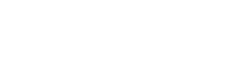

\section{عسمية ومض التأثيرك البيولوجية للإمامكنن بنزولتالنوفاليورهن والدلفلوينزيورن ضند \\ دوة ورق الغان}

ميرفت هسنين أبوالحمد، معتزة عبد الفتاح محمد، داليا لحمد اليب

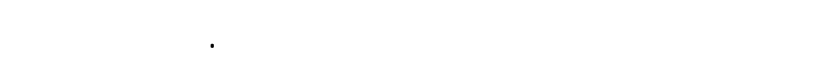
الإملمكتين بنزوات مع الدالفلوبنزيورون أعط ت ت ت أثيرات

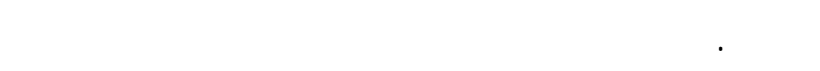

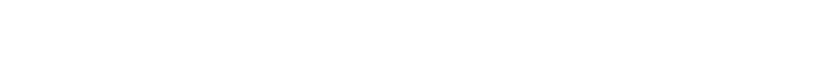

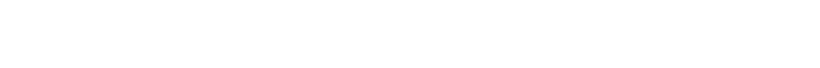

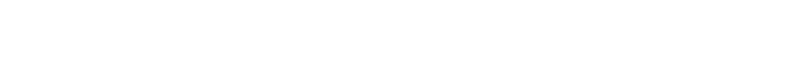

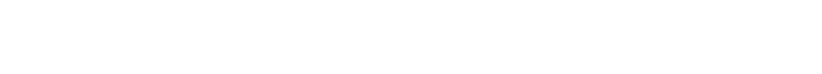

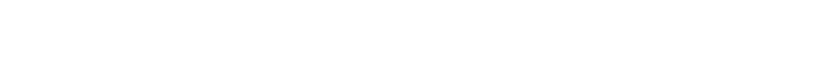

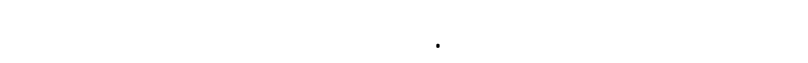

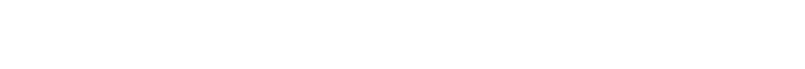

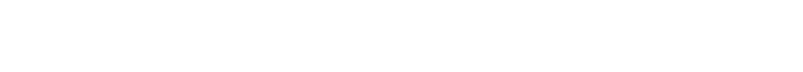
للمبيدات وذك لإختلاف طريقة الفطل للسلم لهذه المبي دات

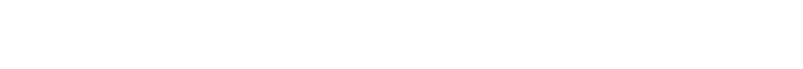
العضوية.
قم قديرسمية وتأثير التركيزات المنغضه على بعض

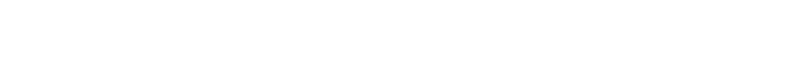

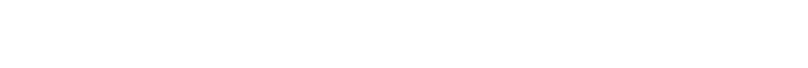

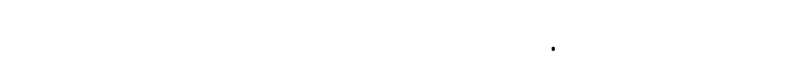

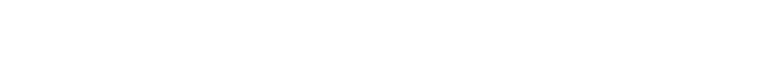

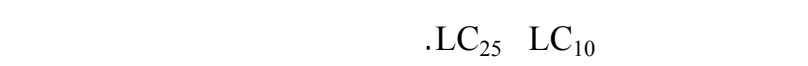

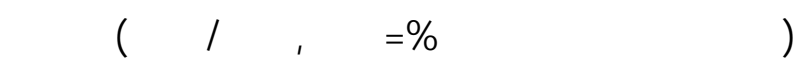

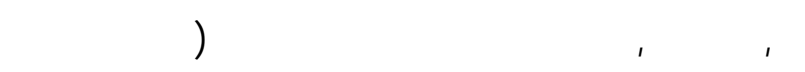

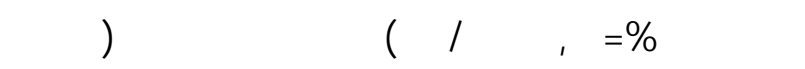

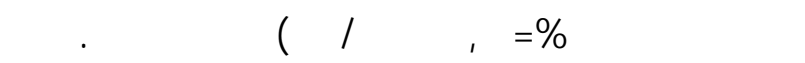

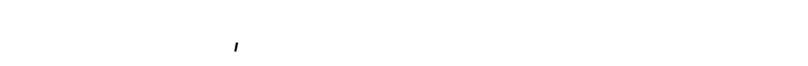

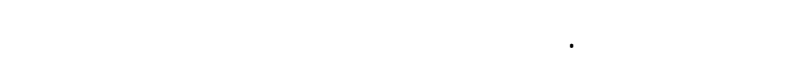

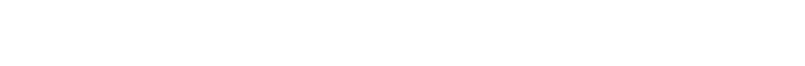

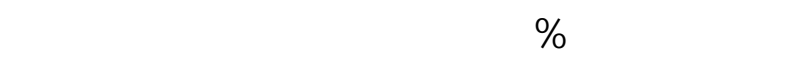

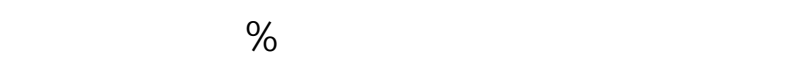

